\title{
The impact of internal multiple attenuation in pre-salt areas of Santos Basin
}

J. Espinoza, I. Zoukaneri, J. Krueger, A. Souza, D. Mondini, T. Le Canu, E. Porto, R. Pereira, J. Manrique, B. Cabral and A. Khalil, CGG

Copyright 2019, SBGf - Sociedade Brasileira de Geofísica

This paper was prepared for presentation during the $16^{\text {th }}$ International Congress of the Brazilian Geophysical Society held in Rio de Janeiro, Brazil, 19-22 August 2019.

Contents of this paper were reviewed by the Technical Committee of the $16^{\text {th }}$ International Congress of the Brazilian Geophysical Society and do not necessarily represent any position of the SBGf, its officers or members. Electronic reproduction or storage of any part of this paper for commercial purposes without the written consent of the Brazilian Geophysical Society is prohibited.

\section{Abstract}

The ultimate goal of seismic imaging is to provide a highquality seismic data for further interpretation and reservoir characterization. In the Santos basin, this goal can be compromised by the presence of strong internal multiples that affect the pre-salt reservoirs. Using the prediction method presented by Krueger et al. (2018), we examine several pre-salt areas in the Santos basin. We present our internal multiple prediction and subtraction strategies, and show the benefits for interpretation, velocity model building and quantitative analysis.

\section{Introduction}

The Santos basin, offshore Brazil, is well known for its giant pre-salt oil fields. While the common geological element of the Santos basin is the presence of a thick salt layer, other geological features of the basin can be varied. In the south-western and central parts, the occurrence of stratified salt is very common. In deeper water areas, there is formation of diapirs and the presence of allocthonous salt. Moreover, volcanic rocks are commonly found in the north-eastern part of the basin (Meisling et al., 2001).

Imaging in this environment is known to be challenging because of strong artifacts generated by internal multiples (Hembd et al., 2011; Cypriano et al., 2015; Krueger et al., 2018). Water bottom (WB), top of salt (TOS), stratified salt, top of Albian, top of Cretaceous, and volcanic rocks are all potential generators of strong internal multiples. Internal multiples may have different implications for seismic imaging. Some multiples directly interfere with the reservoir image, affecting interpretation and quantitative analysis. Other multiples may be misinterpreted as primaries, thus causing errors in velocity estimation. Internal multiple attenuation (IMA) is therefore important for maximizing the value of the seismic product.

For internal multiple prediction, we used the method of van der Neut \& Wapenaar, (2016) (see also Pereira et al., 2018). This method has the advantage of being robust to the different scenarios encountered in the Santos basin. In particular, no explicit definition of generators is required. Subtraction was performed in the image domain using 3D curvelet filters (Ying et al., 2005; Wu and Hung, 2015).

We applied this IMA flow in four areas of the Santos basin (Figure 1). We will highlight our observations and learnings on the impact that IMA has on interpretation, velocity model building and quantitative analysis. All datasets shown here are 3D narrow-azimuth towedstreamer surveys.

\section{Internal multiple prediction and subtraction strategy}

Similar to Jakubowicz (1998), the proposed prediction method (van der Neut \& Wapenaar, 2016; Pereira et al., 2018) is based on a cross-correlation followed by a convolution of the data, together with some mutes designed to prevent primary leakage in the internal multiple model.

The method relies on separating the data between an overburden region and a target region. The overburden region is defined to contain the internal multiple generators, and the target region is where the multiples are imaged. Figure 2 shows a typical configuration in the Santos basin and an example of overburden/target separation.

The horizon separating these two regions can be arbitrary. No strict definition of generators is required. The implementation is shot-based and suitable for large 3D applications. All of these properties satisfy our requirements for IMA in the varied geological scenarios of the Santos basin.

Data preparation included denoise, designature, deghosting, and surface-related multiple attenuation (SRME). Similar to SRME (Dragoset et al., 2010), data must be properly interpolated and the near offsets need to be reconstructed to ensure a good prediction.

Subtraction of internal multiples can be challenging because of the similarity of these multiples with primaries, in terms of amplitude, frequency, apparent dips, etc. We performed the subtraction post-imaging on offset cubes using a method based on the 3D curvelet transform (Ying et al., 2005; Wu \& Hung, 2015). The curvelet-based subtraction has the advantage of minimizing the damage to the primary events, thanks to the intrinsic decomposition of the input data and the multiple model into different dip and frequency bands. Moreover, the use of the 3D transform honors the 3D nature of seismic data. 


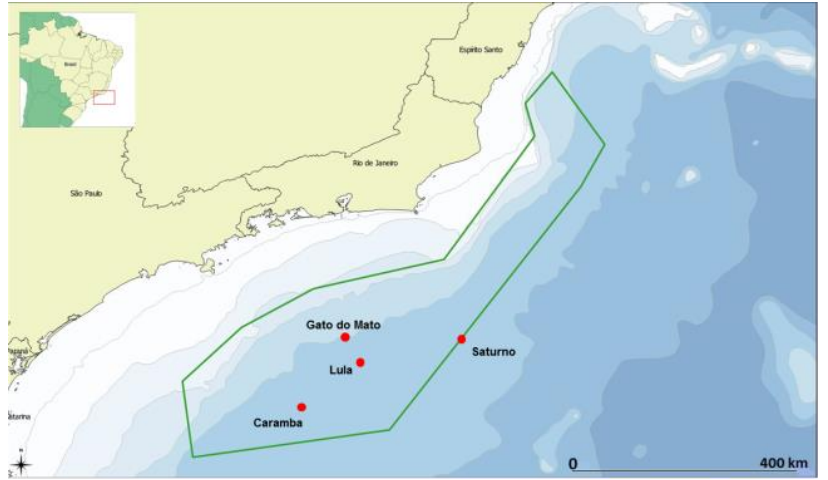

Figure 1 - Map of the South-eastern Brazilian coast presenting the pre-salt polygon (green) and the four analyzed pre-salt areas (red).

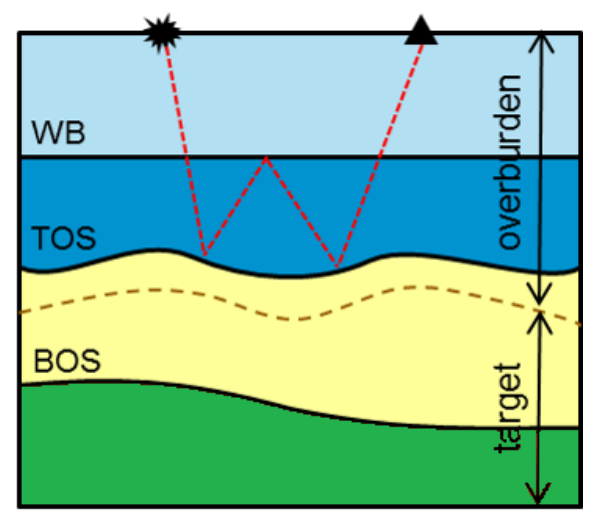

Figure 2 - Typical geological configuration in the Santos basin. An example of an internal multiple is shown in red. A choice of horizon separating overburden/target areas is shown in brown.

\section{IMA for Interpretation: Caramba and Saturno}

Caramba and Saturno are large oil prospects located in the southern and north-eastern parts of the Santos basin (Figure 1).

The Caramba area is characterized by strong impedance contrasts in the stratified salt, which creates a highenergy train of multiples that spread down to the pre-salt level (Figure 3a). Similar to most areas within the Santos basin, we observed the distinctive long-period lowfrequency behavior of the WB-TOS internal multiple crossing the salt section (Figure $3 \mathrm{a}$ ), so we chose a horizon just below TOS to get our first IMA model prediction. Even though this model captured a considerable amount of multiple energy, it is mostly concentrated in the salt level (Figure 3c). To better address the internal multiples that are imaged in the presalt layer, we performed a second modeling using a horizon that lies just above the base of salt (BOS) in order to include the multiples generated by the stratified salt reflectivity. The resulting model (Figure $3 d$ ) is rich in short-period multiples that contaminate the pre-salt image. By combining these two models in the subtraction, we obtained a good result (Figure 3b), allowing us to clarify the base of salt and the pre-salt events. The use of the two models improved the relative amplitude distribution of the modeled multiples, thus enhancing the quality of the subtraction. The common image gathers (CIGs) validated the data quality uplift achieved with the simultaneous subtraction of the two models.

The Saturno prospect lies in the deeper part of the Santos basin towards the edge of the pre-salt polygon. It is surrounded by deep volcanic layers that can generate strong internal multiples. Figure 4a shows an example of a deep internal multiple event, below $8 \mathrm{~km}$ depth, generated by the volcanic layer above, which could be misinterpreted as a real event. Figure $4 \mathrm{c}$ shows the internal multiple model in this area, giving us confidence that this event is indeed an internal multiple. The horizon used to guide the modeling was placed below the top of salt. The result of subtraction is shown in Figure $4 \mathrm{~b}$. If not identified correctly as an internal multiple, this type of event can be misinterpreted as part of the basement or deep sediments, which may lead to misinformed basin modeling and increased risk associated with prospect identification.

\section{IMA for Velocity Model Building: Gato do Mato}

The Gato do Mato prospect lies in the north-central part of the Santos basin (Figure 1). Water bottom as well as top of salt and stratified salt are all possible generators of internal multiples in this area.

We can observe internal multiples generated by heavily stratified salt interfering at the base-of-salt level as indicated by the yellow arrows in Figure $5 \mathrm{a}$. We believe they are short period, as their moveout is close to that of the primaries (Figure $5 b$ ). These internal multiples could directly influence the velocity model building workflow when using ray-based tomography inversion.

Residual moveout (RMO) picked on common image gathers drives the tomographic inversion. A conventional flow includes preconditioning of the CIGs using Radon transform to attenuate undesired multiples before picking RMO information. However, Radon transform cannot properly attenuate short-period multiples such as the ones interfering with the base of salt (Figure $5 \mathrm{a}$ ), because their apparent dips are very similar to primaries. Therefore, the RMO associated with these internal multiples might be included in the inversion and may distort the results. Careful pick editing might help to overcome the problem, but editing can be cumbersome when dealing with large 3D surveys. 


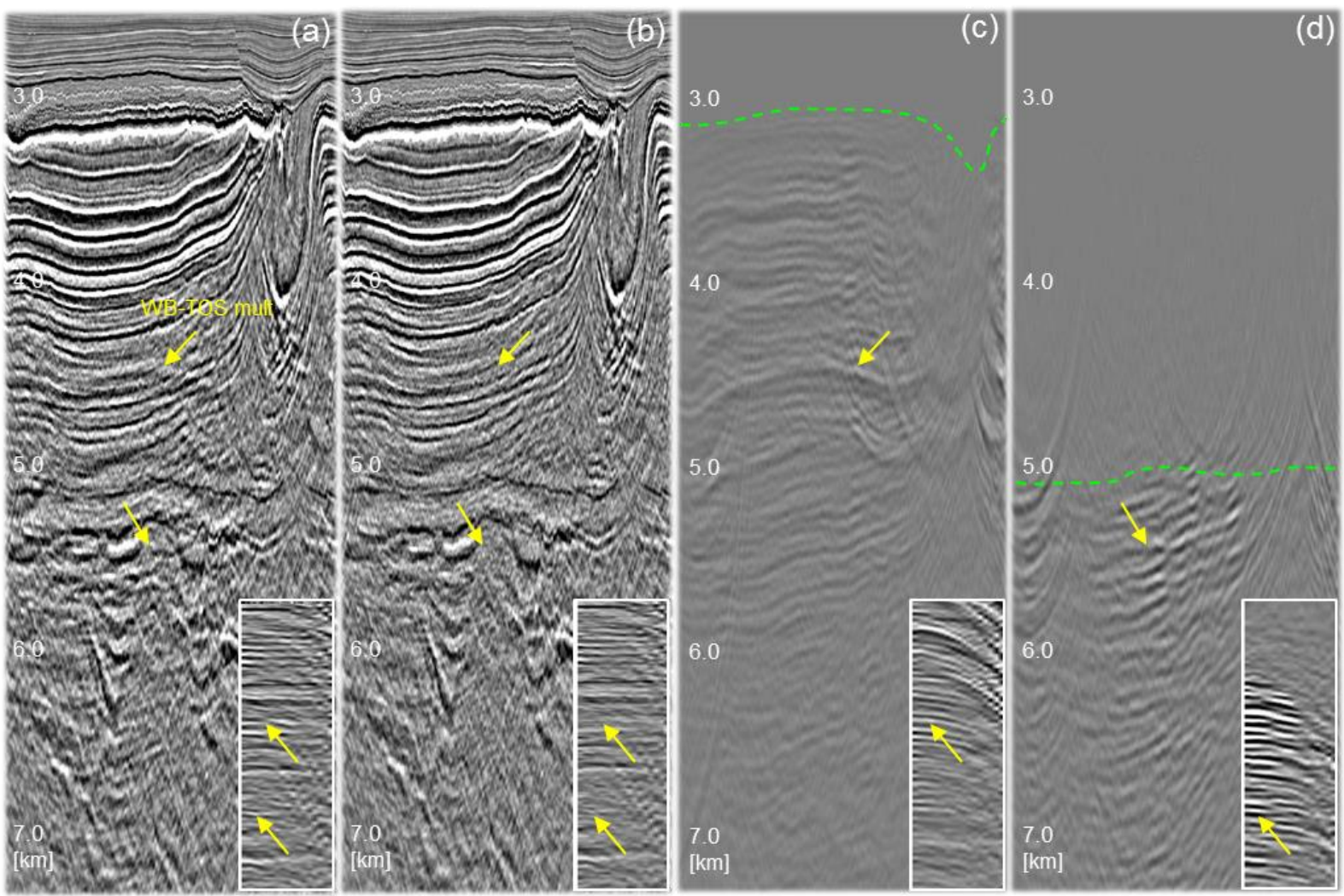

Figure 3 - Internal multiple attenuation in the Caramba area: section from a near-offset cube and gather (inset) before (a) and after (b) IMA using two models (c) and (d). Green dotted lines depict the location of the horizons used during modeling.

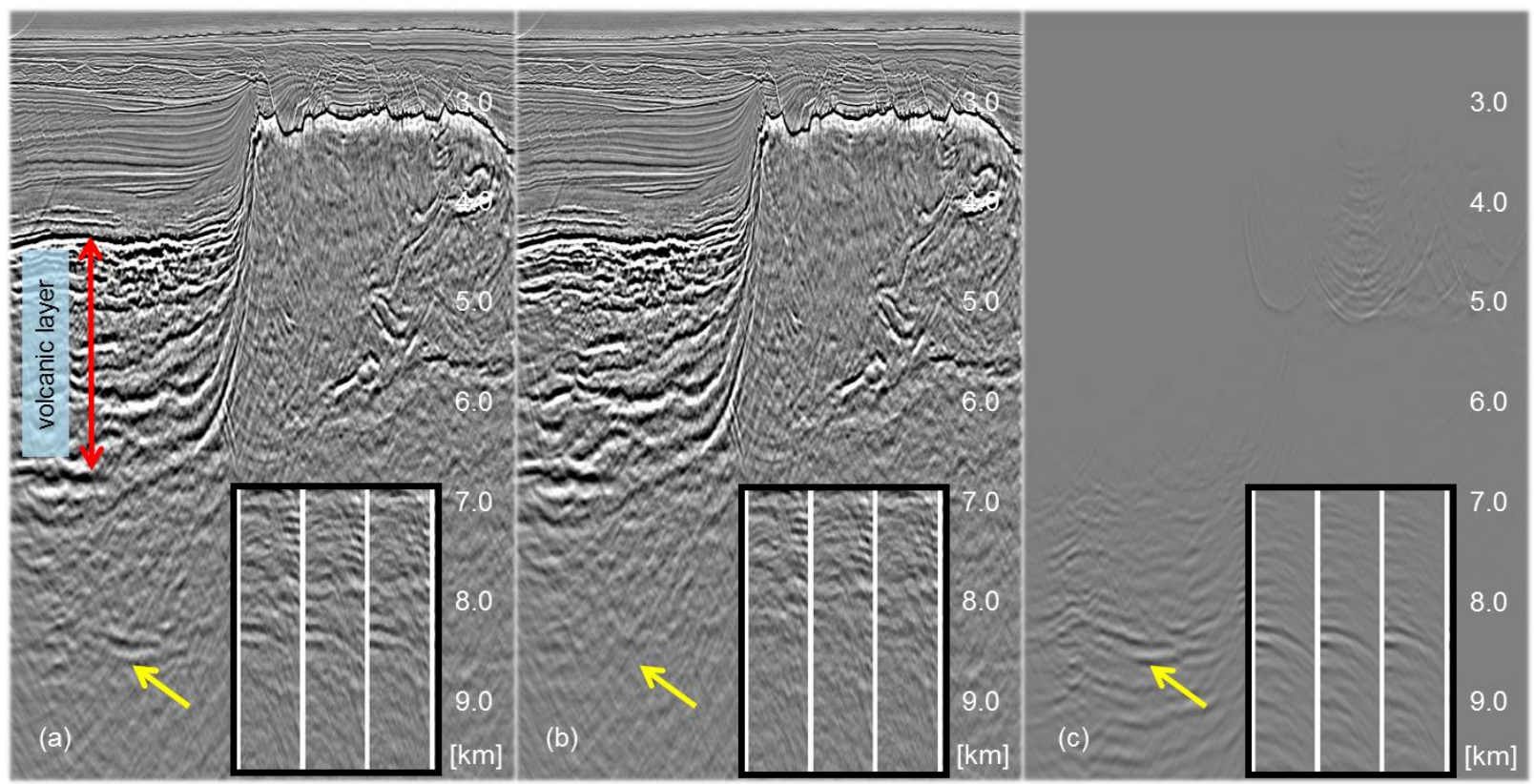

Figure 4 - Internal multiple in the deep region of the Saturno prospect below a thick volcanic layer: (a) and (b) section from near offset cube before and after subtraction; (c) predicted model. The strong deep event, also observed in the gathers view (inset), is successfully removed after IMA; the new image can avoid unrealistic interpretations and provide analysis that is more reliable. 


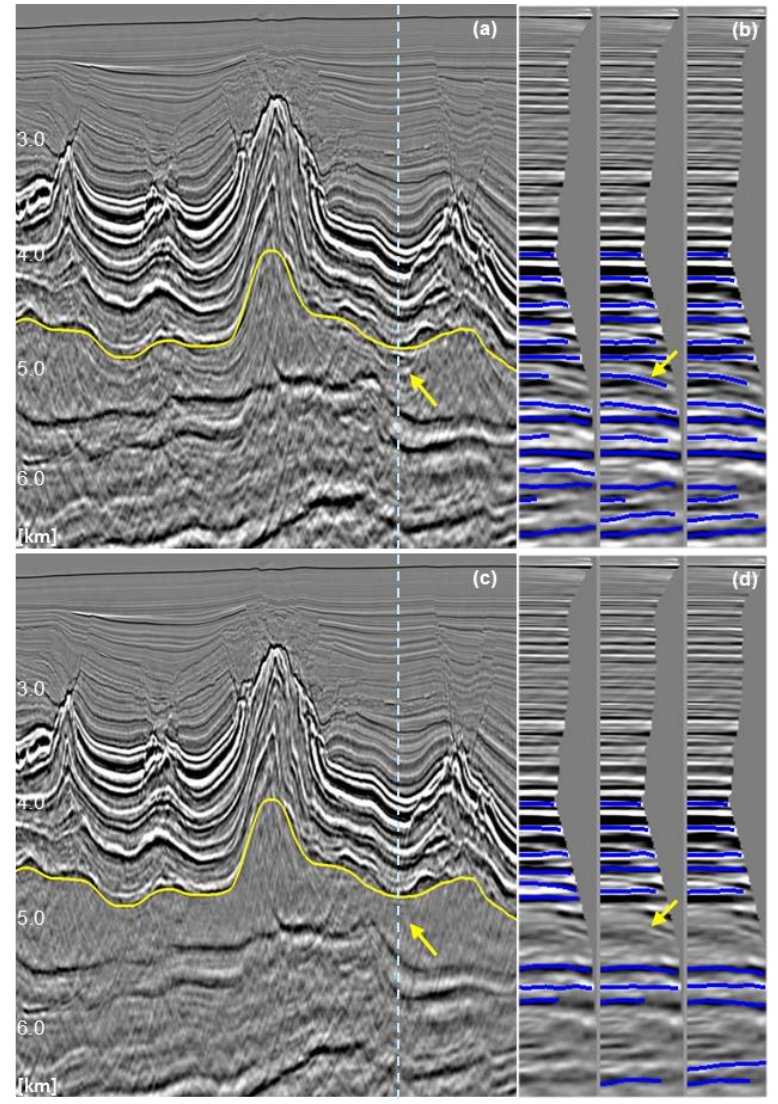

Figure 5 - Example in Gato do Mato prospect showing: (a) section with internal multiples indicated by yellow arrows (the light blue line indicates CIG location); (b) Radon preconditioned CIG superimposed by RMOpicks in blue. The short-period internal multiples have been picked, and might lead to inconsistent velocity; (c) section with IMA applied and removed internal multiples indicated by yellow arrows, the light blue dashed line indicates CIG location (d) Preconditioned CIG using IMA before Radon transform, superimposed by RMO-picks in blue. The short-period internal multiples have been removed, allowing for a more trustworthy velocity model inversion. The deepest horizon to guide the IMA model is shown in yellow.

Figure $5 \mathrm{~b}$ shows Radon preconditioned CIGs from this section overlaid by the RMO picks (in blue). The light blue dashed line in Figure $5 \mathrm{a}$ indicates the gathers' location. The yellow arrows indicate internal multiples that have been picked. Figure $5 \mathrm{~d}$ shows the same gathers with IMA applied prior to Radon pre-conditioning. The corresponding stack image is in Figure 5c. We notice that the short-period multiples have been removed by IMA and the $\mathrm{RMO}$ picks are now mainly related to primaries. The horizon used to guide the IMA model is placed below the top of salt, as shown by the yellow profile in Figures $5 \mathrm{a}$ and $5 \mathrm{c}$.

To assess the impact of IMA on velocity model building, two sets of RMO were picked (with and without internal multiple attenuation, as shown in Figures $5 b$ and $5 d$ ) and we ran a tomographic inversion for each $\mathrm{RMO}$ set.
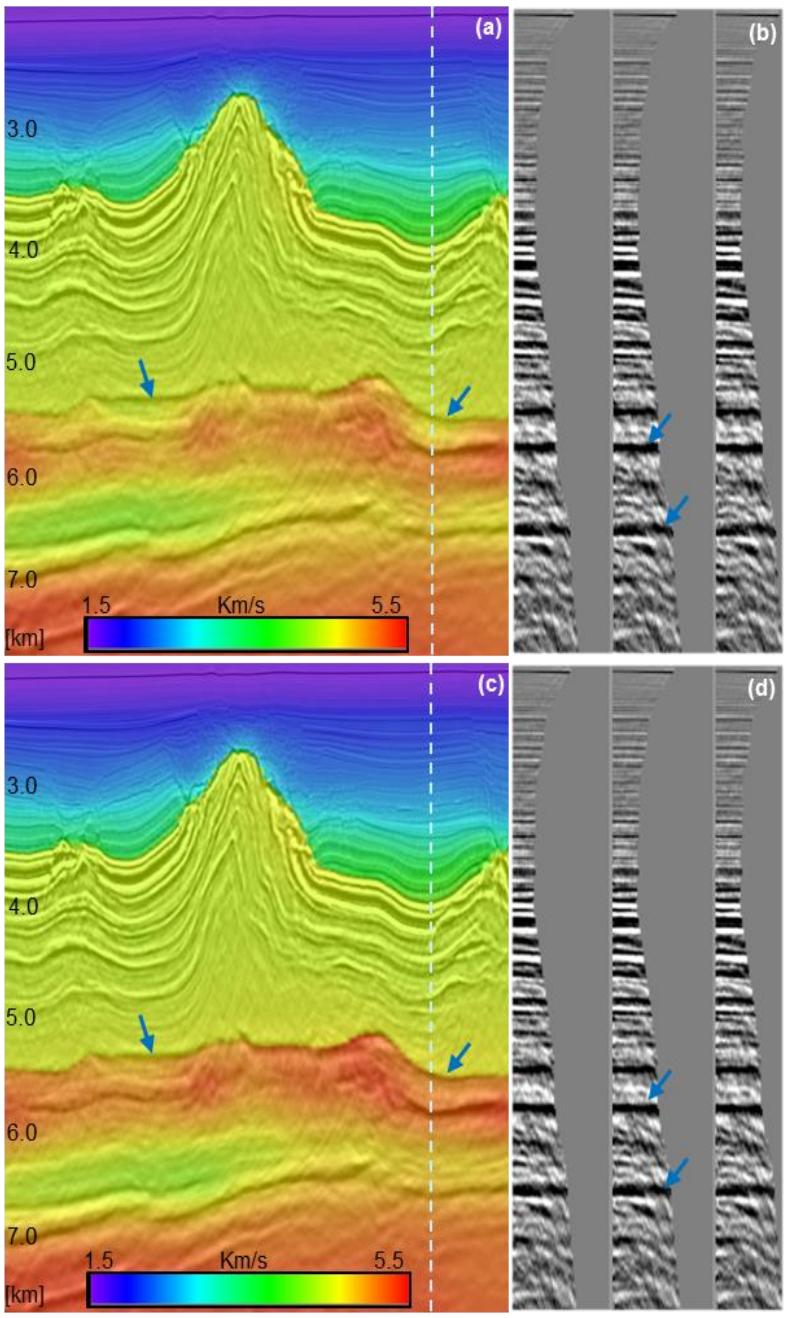

Figure 6 - Velocity models and corresponding migrated gathers obtained using two different set of picks, with (a) and without (b) IMA applied on input CIG. The velocity inversions just below the BOS are reduced when using RMO information from IMA results.

Figure 6 shows the seismic section overlaid with the velocity and the migrated gathers associated with each inverted model. In Figure $6 \mathrm{a}$ we observe that the RMO picks obtained without IMA application produced local variations in the inverted velocity at the base of salt, which affect the geological consistency of the model. On the other hand, by using the picks obtained with the proposed IMA flow, the inverted velocity at base of salt has fewer local inversions and less lateral variation (Figure 6b). The improvement of flatness is mild because of the depth of the pre-salt target; however, the resultant velocity model is more geologically consistent after IMA. This observation confirms that internal multiples can affect model building, and their attenuation could improve the accuracy of the obtained model. 


\section{IMA for Quantitative Analysis: Lula}

Lula is a large oil field in the central part of the Santos basin. This area is characterized by strong impedance contrasts within the stratified salt. If not addressed, internal multiples may interfere with the amplitudes of the pre-salt reservoir, affecting quantitative analysis.

Figure $7 \mathrm{a}$ shows a $5 \mathrm{~km}$ depth slice of the processed area. Internal multiples crossing the main pre-salt structures are indicated by the yellow arrows. Again, two horizons were used in order to guide the internal multiple prediction. The result after subtraction is presented in Figure $7 \mathrm{~b}$. One well in the area affected by multiples was used as reference to assess the quality of the seismic image at this location.

The quantitative analysis first consists in an angledependent well-seismic tie: the synthetic seismograms generated from well logs are compared to the seismic angle sub-stacks extracted at the well location. The correlation between both datasets is scanned by angle and by depth. In parallel, elastic inversion is run around the well: the $\mathrm{Vp} / \mathrm{Vs}$ ratio inverted from the seismic is compared to the $\mathrm{Vp} / \mathrm{Vs}$ ratio measured from well logs (in the seismic bandwidth). Figure 8 shows that the application of IMA allows an increase in the syntheticseismic correlation, in particular below the base of salt, compared to the test without IMA.

On the other hand, the match between the inverted $\mathrm{Vp} / \mathrm{Vs}$ ratio and the $\mathrm{Vp} / \mathrm{Vs}$ ratio measured from well logs increases after application of IMA, leading to the enhanced contrast expected at the base of salt.

This analysis demonstrates that the application of IMA strengthens confidence in the quantitative information that can be extracted from seismic, through a better match with wells at the reservoir level. This confidence is critical for further characterization work such as facies classification, which relies on realistic ranges of elastic values to be trustworthy.

\section{Conclusions}

We have shown that the proposed prediction method gives robust internal multiple predictions for all of the analyzed datasets, and the 3D subtraction strategy in the migrated domain performs well in these different geological scenarios.

We have shown that IMA increases seismic interpretability value, raises the reliability of pre-salt imaging, and allows an improved delineation of the base of salt. Far from the reservoir, we have seen that basin modelling also benefits from IMA by helping in the discrimination of basement structures.
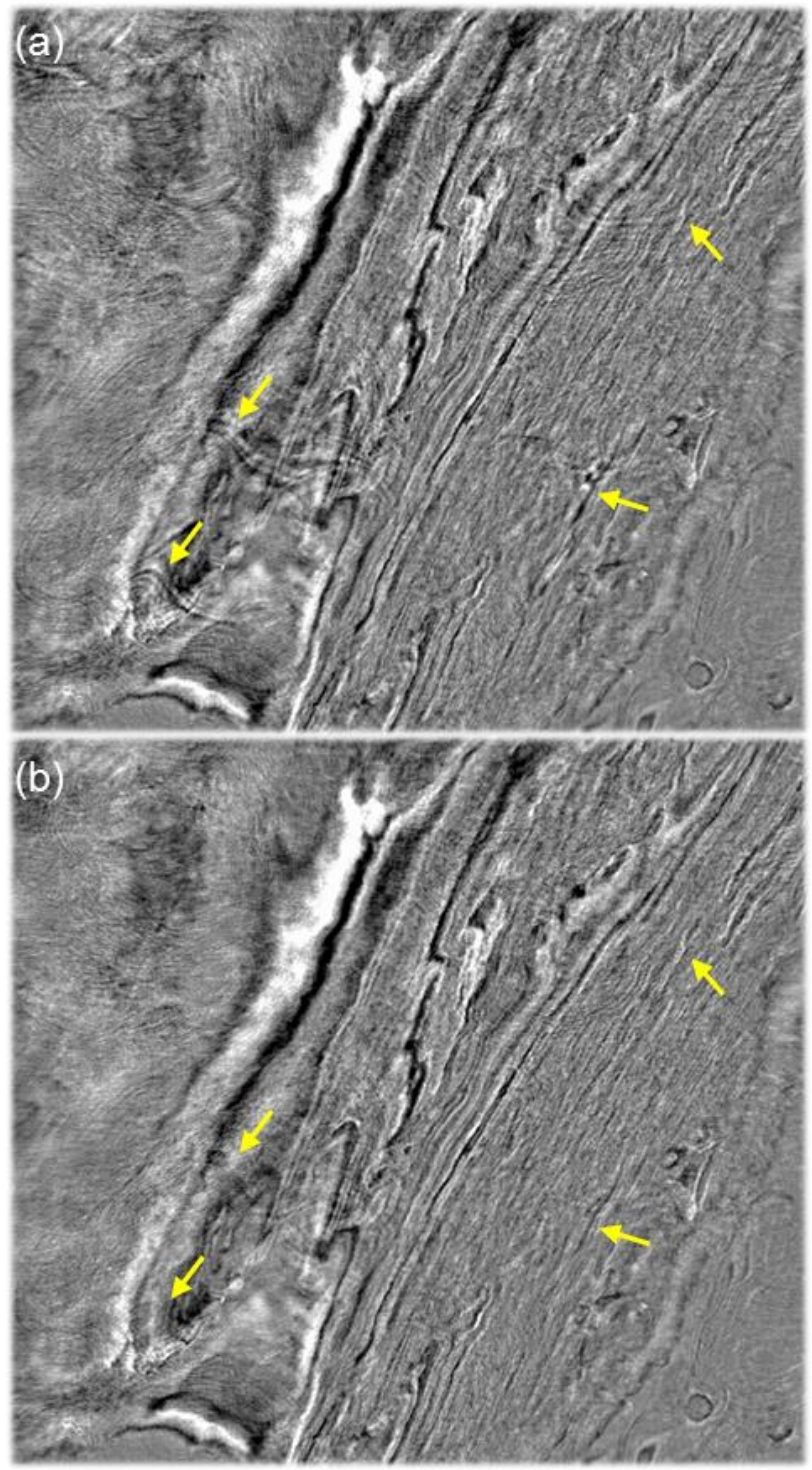

Figure 7 - Seismic depth slice at $5 \mathrm{~km}$ in Lula field (a) before and (b) after IMA application. The internal multiples indicated by yellow arrows cross the pre-salt events and can not only lead to confusing interpretation but can also affect the quantitative analysis.

In terms of velocity model building, the attenuation of internal multiples is key to avoiding inaccuracies (caused by picking $\mathrm{RMO}$ from multiples) on the inverted velocity. Results showed that, after applying IMA to CIGs used in tomographic inversion, the obtained velocity better follows the structures and is less affected by instabilities that might create local velocity inversions.

Finally, we have evaluated the effect of IMA on quantitative analysis, improving the reliability of the reservoir, with higher seismic-synthetic correlation and better $\mathrm{Vp} / \mathrm{Vs}$ inversion. 


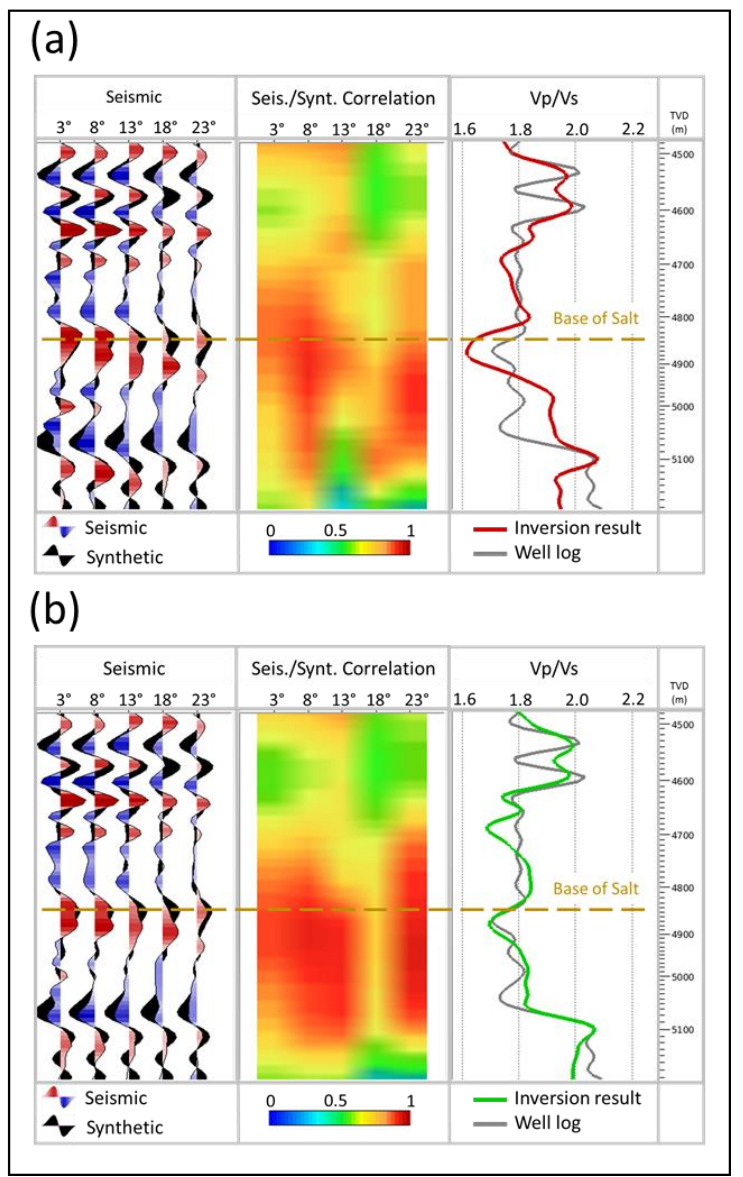

Figure 8 - Quantitative analysis in Lula field (a) without IMA and (b) with IMA. Higher correlations indicate that synthetic-seismic match has been improved after IMA application, especially below BOS. The match between $\mathrm{Vp} / \mathrm{Vs}$ ratio inverted from seismic and $\mathrm{Vp} / \mathrm{Vs}$ ratio measured from well logs also increases after IMA application.

\section{Acknowledgments}

The authors thank CGG for permission to publish this work and CGG Multi-Client \& New-Ventures for the Santos basin datasets. Special thanks to Daniela Donno for actively collaborating in the preparation of this document.

\section{References}

CYPRIANO, L., F. MARPEAU, R. BRASIL, G. WELTER, H. PIGENT, H. DOUMA, M. VELASQUES, J. BOECHAT, P. DE CARVALHO, C. GUERRA, \& C. THEODORO, 2015, The impact of inter-bed multiple attenuation on the imaging of pre-salt targets in the Santos basin off-shore Brazil: 77th EAGE Conference \& Exhibition, Extended Abstracts, N114-06.
DRAGOSET, B., E. VERSCHUUR, I. MOORE, \& R. BISLEY, 2010, A perspective on 3D surface-related multiple elimination: Geophysics, 75(5), A245-A261.

HEMBD, J., M. GRIFFITHS, C. TING, \& N. CHAZALNOEL, 2011, Application of 3D interbed multiple attenuation in the Santos Basin, Brazil: 73rd EAGE Conference and Exhibition, Extended Abstracts, H047.

JAKUBOWICZ, H., 1998, Wave equation prediction and removal of interbed multiples: 68th SEG Annual International Meeting, Expanded Abstracts, 1527-1530.

KRUEGER, J., D. DONNO, R. PEREIRA, D. MONDINI, A. SOUZA, J. ESPINOZA \& A. KHALIL, 2018, Internal multiple attenuation for four presalt fields in the Santos basin, Brazil, 88th SEG Annual International Meeting, Expanded Abstracts, 4523-4527.

MEISLING, K. E., P. R. COBBOLD, \& V. S. MOUNT, 2001, Segmentation of an obliquely rifted margin, Campos and Santos basins, southeastern Brazil: AAPG Bulletin, 85(11), 1903-1924.

PEREIRA, R., D. MONDINI, \& D. DONNO, 2018, Efficient 3D internal multiple attenuation in the Santos basin: 80th EAGE Conference and Exhibition, Extended Abstracts, We-C-08.

VAN DER NEUT, J., \& K. WAPENAAR, 2016, Adaptive overburden elimination with the multidimensional Marchenko equation: Geophysics, 81(5), T265-T284.

WU, X., \& B. HUNG, 2015, High-fidelity adaptive curvelet domain primary-multiple separation: First Break, 33(1), 53-59.

YING, L., L. DEMANET, \& E. CANDES, 2005, 3D discrete curvelet transform: Wavelets XI, International Society for Optics and Photonics, 5914, 591413. 